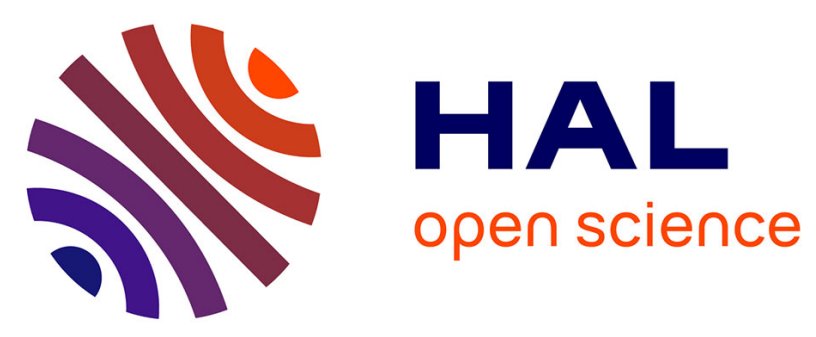

\title{
Comparative effect of hypothermia and adrenaline during cardiopulmonary resuscitation in rabbits.
}

Matthias Kohlhauer, Lys Darbera, Fanny Lidouren, Mourad Chenoune, Bijan

Ghaleh, Benoit Vivien, Pierre Carli, Hubert Dabire, Alain Berdeaux, Renaud

Tissier

\section{To cite this version:}

Matthias Kohlhauer, Lys Darbera, Fanny Lidouren, Mourad Chenoune, Bijan Ghaleh, et al.. Comparative effect of hypothermia and adrenaline during cardiopulmonary resuscitation in rabbits.: Intra-arrest hypothermia and cold saline infusion. Shock, 2014, 41 (2), pp.154-8. 10.1097/SHK.0000000000000083 . inserm-01011114

\section{HAL Id: inserm-01011114 https://www.hal.inserm.fr/inserm-01011114}

Submitted on 23 Jun 2014

HAL is a multi-disciplinary open access archive for the deposit and dissemination of scientific research documents, whether they are published or not. The documents may come from teaching and research institutions in France or abroad, or from public or private research centers.
L'archive ouverte pluridisciplinaire HAL, est destinée au dépôt et à la diffusion de documents scientifiques de niveau recherche, publiés ou non, émanant des établissements d'enseignement et de recherche français ou étrangers, des laboratoires publics ou privés. 
1

$9{ }^{1}$ Inserm, U955, Equipe 3, Créteil, 94000, France

\section{No conflict of interest} France Université Paris Descartes - Paris V, Paris, 75015, France

\section{Corresponding author:}

Renaud TISSIER, DVM, PhD

INSERM U955, Equipe 3 ; Faculté de Médecine de Créteil

8 rue du Général Sarrail ; 94010 Créteil cedex, France

\section{Comparative effect of hypothermia and adrenaline} during cardiopulmonary resuscitation in rabbits Alain Berdeaux ${ }^{1,2,3}$, Renaud Tissier 1,2,3

2 Université Paris Est, Faculté de Médecine, Créteil, 94000, France

3 Université Paris Est, Ecole Nationale Vétérinaire d'Alfort, Maisons-Alfort, 94700,

${ }^{4}$ SAMU de Paris, Département d'Anesthésie Réanimation, CHU Necker Enfants Malades,

Running title: Intra-arrest hypothermia and cold saline infusion

Tel : +33.1.43.96.73.02 ; Fax : +33.1.43.96.17.77 ; E-mail: rtissier@vet-alfort.fr

Funding sources: Grant (ABYSS-R12031JJ) from the "Agence Nationale pour la Recherche" (Paris, France). M. Kohlhauer was supported by a grant from the "Région Ilede-France" (CORDDIM). R. Tissier was recipient of a "Contrat d'Interface INSERM-ENV". 


\section{Abstract (250 words)}

Introduction: Therapeutic hypothermia was shown to facilitate resumption of spontaneous circulation (ROSC) when instituted during cardiac arrest. Here, we investigated whether it directly improved the chance of successful resuscitation independently of adrenaline administration in rabbits. We further evaluated the direct effect of hypothermia on vascular function in vitro.

Methods: In a first set of experiments, four groups of anaesthetized rabbits were submitted to 15 min of cardiac arrest and subsequent cardiopulmonary resuscitation (CPR). The "Control" group underwent CPR with only cardiac massage and defibrillation attempts. Two other groups received cold or normothermic saline infusion during CPR (20 ml/kg of $\mathrm{NaCl} 0.9 \%$ at $4^{\circ} \mathrm{C}$ or $38^{\circ} \mathrm{C}$, respectively). In a last group, the animals received adrenaline (15 $\mu \mathrm{g} / \mathrm{kg}$ i.v.) during CPR. In a second set of experiments, we evaluated at 32 vs $38^{\circ} \mathrm{C}$ the vascular function of aortic rings withdrawn from healthy rabbits or after cardiac arrest.

Results: In the first set of experiments, cardiac massage efficiency was improved by adrenaline but neither by hypothermic nor normothermic saline administration. ROSC was observed in 5/8 animals after adrenaline as compared to $0 / 8$ in other groups. Defibrillation rates were conversely similar among groups (7/8 or $8 / 8)$. In the second set of experiments, in vitro hypothermia $\left(32^{\circ} \mathrm{C}\right)$ was not able to prevent the dramatic alteration of vascular function observed after cardiac arrest. It also not directly modified vasocontractile nor vasodilating functions in healthy conditions.

Conclusion: In rabbits, hypothermia did not exert a direct hemodynamic or vascular effect that might explain its beneficial effect during CPR. 


\section{Key Words}

53 Cooling, Cardiac arrest, Ventricular fibrillation, Fluid, Cardiac massage, Animal Study. 54 


\section{INTRODUCTION}

It is well admitted that therapeutic hypothermia $\left(32^{\circ} \mathrm{C}-34^{\circ} \mathrm{C}\right)$ improves the prognosis and the neurologic recovery of comatose survivors after cardiac arrest ${ }^{1-3}$. A maximal neurological ${ }^{4-7}$ and cardiovascular ${ }^{8-10}$ protection is obtained when hypothermia is started as soon as possible, e.g., using cold saline infusion during cardiopulmonary resuscitation (CPR). The so-called "intra-arrest" hypothermia was shown to facilitate resumption of spontaneous circulation (ROSC) in rodents and porcine models ${ }^{6,11}{ }^{\text {. Two }}$ recent observational studies corroborate these results by the demonstration of a higher frequency of ROSC in patients receiving hypothermia through cold saline infusion during CPR as compared to standard care ${ }^{12,13 .}$

To our knowledge, the exact mechanism underlying the effect of therapeutic hypothermia on ROSC remains still unknown but several hypotheses have been made. In pigs, hypothermia was shown to improve the response to defibrillation attempts ${ }^{6,11}$ and decrease the amount of adrenaline required to achieve ROSC 6 . Hypothermia was also reported to improve systemic hemodynamics by increasing arterial resistances ${ }^{14}$. In animal models, the influence of hypothermia on vessel function and hemodynamics was however investigated when combined to adrenaline, which could alter the exact role played by therapeutic hypothermia 6, 15-17. The aim of the present study was to investigate the intrinsic vascular effect of hypothermia during CPR. Accordingly, we investigated the effect of therapeutic hypothermia induced by cold saline infusion on cardiac massage efficiency in rabbits without adrenaline administration. In order to determine the real effect of hypothermia versus that of fluid loading, we compared cold saline to warm saline infusion. We finally included a group with adrenaline administration alone, as a positive control of efficient CPR. Our end-points were cardiac massage efficiency assessed by hemodynamic parameters, rate of defibrillation success 
80 and ROSC occurrence. In addition, we also examined the direct effect of hypothermia

$81\left(32^{\circ} \mathrm{C}\right.$ vs $\left.38^{\circ} \mathrm{C}\right)$ on the vascular response of isolated vessels after cardiac arrest in 82 rabbits.

83 


\section{MATERIALS AND METHODS}

The animal instrumentation and the ensuing experiments were conducted in accordance with French official regulations, after approval by the local ethical committee (ComEth AnSES/ENVA/UPEC n¹6).

\section{Animal preparation and cardiac arrest procedure}

Male New Zealand rabbits $(2.5-3.0 \mathrm{~kg}$ ) were anaesthetized using zolazepam, tiletamine and pentobarbital (all $20-30 \mathrm{mg} / \mathrm{kg}$ i.v.). After intubation and initiation of mechanical ventilation $\left(\mathrm{FiO}_{2}=30 \%\right)$, two central catheters were inserted in the carotid artery and jugular vein for measurements of central arterial and venous pressures, respectively. Two electrodes were implanted upon the chest and inserted into the oesophagus. After a period of stabilization, ventricular fibrillation was induced by an alternative current (10 V, $4 \mathrm{~mA})$ between the two electrodes. Mechanical ventilation was stopped throughout the cardiac arrest period. After 15 min of untreated cardiac arrest,

CPR was initiated using cardiac massage $(\sim 200$ beats/min) and restoration of a continuous oxygen flow $\left(\mathrm{FiO}_{2}=100 \%\right)$. Electric attempts of defibrillations $(10 \mathrm{~J} / \mathrm{kg})$ were started at the $3^{\text {rd }}$ min of CPR and repeated every 2 min until ROSC, which was considered as an organized cardiac rhythm with a systolic arterial pressure above $40 \mathrm{mmHg}$ during at least $1 \mathrm{~min}$.

\section{Experimental protocol}

In addition to basic life support and electric attempts of defibrillation, rabbits were randomly assigned to one experimental group (Figure 1A). The Control group did not receive any additional procedure. In the "Saline $4^{\circ} \mathrm{C}$ " and "Saline $38^{\circ} \mathrm{C}$ " groups, the animals received $20 \mathrm{ml} / \mathrm{kg}$ of $\mathrm{NaCl}\left(0.9 \%\right.$ at $4^{\circ} \mathrm{C}$ or $38^{\circ} \mathrm{C}$, respectively) from the $1^{\text {st }}$ to the $3^{\text {rd }}$ min of CPR. The last group received bolus administrations of adrenaline $(15 \mu \mathrm{g} / \mathrm{kg}$ i.v.) every 2 min until occurrence of ROSC. In the Control group, as well as in "Saline $4^{\circ} \mathrm{C}^{\prime}$ 
109

110

111

112

113

114

115

116

117

and "Saline $38^{\circ} \mathrm{C}$ " groups, no any vasopressor drug was used. Resuscitation efforts were stopped after 10 min of unsuccessful CPR or in case of haemoptysis.

Throughout the protocol, rectal, oesophageal and tympanic temperatures were monitored using thermal probes (Harvard Apparatus, Paris, France). Hemodynamic parameters were also continuously recorded using external electrocardiogram, arterial and venous blood pressures in the right carotid and jugular vein, respectively. The difference between arterial and venous pressures was calculated with the data acquisition software HEM version 3.5 (Notocord, Croissy-sur-Seine, France). End-tidal $\mathrm{CO}_{2}$ concentration in the expired air $\left(\mathrm{EtCO}_{2}\right)$ and blood oxygen saturation $\left(\mathrm{SpO}_{2}\right)$ were continuously assessed. The primary end-point of the study was the percentage of animals achieving ROSC in each group. Defibrillation success and hemodynamic parameters were secondary end-points.

In vitro analysis of vascular function

Additional rabbits were anaesthetized and intubated as described above. They were randomly submitted to a "Sham" procedure without any cardiac arrest or to $15 \mathrm{~min}$ of untreated ventricular fibrillation as previously described. In the latter case, animals were resuscitated using cardiac massage, electric attempts of defibrillation and adrenaline administration. After ROSC, the animals were monitored during 6 hours with constant adrenaline infusion in order to avoid hypotension if necessary. If necessary, anesthesia was maintained using pentobarbital administration. Animals were then euthanized and the descending thoracic aorta was removed and cleaned of connective tissues. Aorta rings were mounted in isolated vessels chambers, as previously described ${ }^{18}$. After $120 \mathrm{~min}$ of equilibrium under resting tension of $2 \mathrm{~g}$, the chamber temperature was randomly adjusted at either $32^{\circ} \mathrm{C}$ or $38^{\circ} \mathrm{C}$. Thirty minutes later, the response to increasing concentrations of noradrenaline was evaluated $[0.3,1$ and 
$1343 \mu \mathrm{mol} / \mathrm{L})$. The endothelial-dependent and independent relaxation was then assessed

135 using acetylcholine (0.1 mmol/L) and sodium nitroprusside $(0.1 \mathrm{mmol} / \mathrm{L})$, respectively.

136 The experiments were repeated at two levels of temperature $\left(32\right.$ or $\left.38^{\circ} \mathrm{C}\right)$.

$137 \quad$ Statistical analysis

138 Data were expressed as mean \pm SEM. Temperatures, hemodynamic and in vitro 139 parameters were compared between the different groups using a two-way ANOVA for 140 repeated measures followed by a Fisher LSD post-hoc analysis. The time to achieve 141 successful defibrillation were compared between groups using a log-rank test. A similar 142 analysis was used for the time to ROSC. The rate of successful defibrillation and ROSC 143 were compared using a Chi-square test. The corresponding Kaplan-Meier curves were 144 drawn. Significant differences were determined at $\mathrm{p} \leq 0.05$. 
146

147

148

149

150

151

152

153

154

155

156

157

158

159

160

161

162

163

164

165

166

167

168

\section{RESULTS}

In vivo investigations

Thirty-two rabbits were randomly included in the different groups $(n=8$ in each group). As illustrated in Figure 1B, the esophageal, tympanic and rectal temperatures were not significantly different among groups at baseline. During CPR, a significant and expected decrease was observed for oesophageal and tympanic temperatures in the

"Saline $4^{\circ} \mathrm{C}$ " group as compared to all other groups. The rectal temperature was still not significantly different among the 4 groups.

As shown in Table 1, hemodynamic parameters, $\mathrm{SpO}_{2}$ and $\mathrm{EtCO}_{2}$ were not different among groups at baseline. After the onset of CPR, cardiac massage efficiency was greater in the "Adrenaline" group as compared to the 3 other groups as evidenced by a significant increase in arterial blood pressure and in the maximal difference between arterial and venous pressures. These parameters were conversely not significantly modified in the two "Saline" groups as compared to the "Control" group.

As illustrated in Figure 2, electric attempts of defibrillation led to a high and similar rate of successful defibrillation in all groups $\left(7 / 8\right.$ animals in the "Control", "Saline $4^{\circ} \mathrm{C}^{\prime}$ and "Adrenaline" groups; 6/8 in the "Saline $38^{\circ} \mathrm{C}$ " groups, respectively). However, no animal elicited successful ROSC in the "Control", "Saline $4^{\circ} \mathrm{C}$ " and "Saline $38^{\circ} \mathrm{C}$ " whereas 5/8 rabbits achieved ROSC in the "Adrenaline" group. In the "Saline $38^{\circ} \mathrm{C}$ " group, resuscitation efforts were interrupted in 3 rabbits after occurrence of haemoptysis. In vitro investigations

Experiments were conducted in 15 and 14 aorta rings sampled from 3 rabbits under sham condition and 4 others after cardiac arrest, respectively. In the rabbits submitted to cardiac arrest, the total dose of adrenaline administered in vivo before euthanasia was $990 \pm 179 \mu \mathrm{g} / \mathrm{kg}$. As illustrated in Figure 3A, the noradrenaline administration induced a 
171 concentration-dependent contraction in vitro in all groups. This effect was however 172 significantly attenuated after cardiac arrest as compared to sham condition but this was 173 not modified by temperature $\left(32\right.$ vs $\left.38^{\circ} \mathrm{C}\right)$. The endothelium-dependent relaxation in 174 response to acetylcholine was also significantly altered after cardiac arrest but remained 175 unchanged regardless the chamber temperature (figure 3B). Endothelium-independent 176 relaxation after sodium nitroprusside administration was maximal and identical in all 177 conditions.

178

179

180 
181

182

183

184

185

186

187

188

\section{DISCUSSION}

The present study demonstrates that hypothermia induced by cold saline infusion neither affected defibrillation success, ROSC frequency nor cardiac massage efficiency in rabbits. Pure fluid loading through warm saline infusion was also inefficient whereas adrenaline administration improved cardiac massage efficiency and rate of ROSC. To our knowledge, this is the first study to specifically address the effect of cold or warm fluid loading with no concomitant administration of adrenaline during CPR in animals. Previous studies rather investigated the role of hypothermia "on top of" adrenaline administration $6,8,11,15,19-22$. In our experimental conditions, mild hypothermia did also not affect vessel reactivity in isolated aorta after cardiac arrest.

The most important finding of this study is the lack of effect of hypothermia on ROSC occurrence when applied alone, i.e., without adrenaline administration. In a recent review, Scolletta et al. showed that hypothermia conversely facilitates ROSC in pigs and rodents when it was combined to adrenaline administration ${ }^{19}$. The rate of ROSC was for example improved with cold blanket cutaneous application ${ }^{11}$, cold saline infusion 6 , hypothermic liquid ventilation 15, 20, trans-nasal evaporation cooling 21,22 or endovascular cooling 8 in pigs. Interestingly, this was often attributed to defibrillation facilitation during hypothermia 6,11. As example, Boddicker et al. demonstrated that hypothermia dramatically improved the chance of defibrillation in a swine model of refractory ventricular fibrillation 11. Menegazzi et al. also demonstrated that hypothermic CPR reduced the decay of ECG waveforms and subsequently improved the rate of successful defibrillation ${ }^{6}$. In our study, it was not possible to show a similar benefit since the rate of successful defibrillation was virtually maximal in Control conditions. 
Another apparent discrepancy is the lack of effect of hypothermia on cardiac massage efficiency, as observed in a previous pig study ${ }^{15}$. Indeed, neither cold saline during CPR. This could be in part related to the proper effect of fluid loading which could compromise the direct effect of cardiac hypothermia. Indeed, Riter et al. showed that a

210 load-independent cooling strategy (hypothermic liquid ventilation) could improve coronary perfusion pressure during CPR as compared to cold saline infusion. In our

212 study, the appearance of several cases of haemoptysis also suggests a poor tolerance of 213 fluid loading after warm saline infusion. It was not possible to directly assess coronary 214 perfusion pressure in the present study since this is technically challenging in the rabbit 215 model 15, 23, 24. The difference between arterial and venous central pressures could 216 however be considered as an indirect evaluation. In accordance with the previous 217 findings of Riter et al. 15 in pigs, it was not modified by hypothermic fluid loading, this is 218 actually in accordance.

219 In the present study, we did not investigate the combined effect of hypothermia and 220 adrenaline in vivo as the latter was too efficient by itself. Any improvement in the rate of 221 ROSC would therefore be hard to evidence in such experimental conditions. We 222 proposed to address this issue in vitro through the determination of the temperature 223 effect on the vascular response to adrenergic stimulation. These experiments clearly 224 showed a lack of effect of temperature $\left(32\right.$ vs $\left.38^{\circ} \mathrm{C}\right)$ on the vascular response to 225 noradrenaline, while cardiac arrest dramatically altered vascular function. The latter 226 result could be either attributed to tachyphylaxis and desensitization after adrenaline 227 administration or to an actual vascular dysfunction, as described regarding 228 microcirculation in patients after cardiac arrest ${ }^{25}$. With lower temperatures, Mustafa 229 and Thulesius interestingly showed that profound hypothermia $\left(27^{\circ} \mathrm{C}\right.$ and $\left.10^{\circ} \mathrm{C}\right)$ altered 
230 the response to noradrenaline of isolated carotids arteries ${ }^{16}$. The cutaneous application 231 of low temperatures (e.g., ice packs) is also well known to induce superficial 232 vasoconstriction 14,26 .

233 In conclusion, cold saline infusion in the absence of adrenaline administration did 234 not improve ROSC occurrence in rabbits. One could speculate that fluid loading hidden 235 the beneficial effect of temperature reduction in this model.

236

237

238

239 


\section{REFERENCE}

241 1. Bernard SA, Gray TW, Buist MD, Jones BM, Silvester W, Gutteridge G, Smith K:

242 Treatment of comatose survivors of out-of-hospital cardiac arrest with induced 243 hypothermia. N Engl J Med 346 (8):557-563, 2002.

244 2. The Hypothermia After Cardiac Arrest Study Group: Mild therapeutic hypothermia to 245 improve the neurologic outcome after cardiac arrest. N Engl J Med 346 (8):549-556, 2462002.

247 3. Nolan JP, Soar J, Zideman DA, Biarent D, Bossaert LL, Deakin C, Koster RW, Wyllie J, 248 Bottiger B: European Resuscitation Council Guidelines for Resuscitation 2010 Section 1. 249 Executive summary. Resuscitation 81 (10):1219-1276, 2010.

250 4. Abella BS, Zhao D, Alvarado J, Hamann K, Vanden Hoek TL, Becker LB: Intra-arrest 251 cooling improves outcomes in a murine cardiac arrest model. Circulation 109 (22):2786$252 \quad 2791,2004$.

253 5. Nozari A, Safar P, Stezoski SW, Wu X, Kostelnik S, Radovsky A, Tisherman S, Kochanek 254 PM: Critical time window for intra-arrest cooling with cold saline flush in a dog model of 255 cardiopulmonary resuscitation. Circulation 113 (23):2690-2696, 2006.

256 6. Menegazzi JJ, Rittenberger JC, Suffoletto BP, Logue ES, Salcido DD, Reynolds JC, 257 Sherman LD: Effects of pre-arrest and intra-arrest hypothermia on ventricular 258 fibrillation and resuscitation. Resuscitation 80 (1):126-132, 2009.

259 7. Chenoune M, Lidouren F, Adam C, Pons S, Darbera L, Bruneval P, Ghaleh B, Zini R, 260 Dubois-Rande JL, Carli P, Vivien B, Ricard JD, Berdeaux A, Tissier R: Ultrafast and whole261 body cooling with total liquid ventilation induces favorable neurological and cardiac 262 outcomes after cardiac arrest in rabbits. Circulation 124 (8):901-911, 901-907, 2011. 
263 8. Yannopoulos D, Zviman M, Castro V, Kolandaivelu A, Ranjan R, Wilson RF, Halperin

264 HR: Intra-cardiopulmonary resuscitation hypothermia with and without volume loading

265 in an ischemic model of cardiac arrest. Circulation 120 (14):1426-1435, 2009.

266 9. Zhao D, Abella BS, Beiser DG, Alvarado JP, Wang H, Hamann KJ, Hoek TL, Becker LB:

267 Intra-arrest cooling with delayed reperfusion yields higher survival than earlier 268 normothermic resuscitation in a mouse model of cardiac arrest. Resuscitation 77 269 (2):242-249, 2008.

270 10. Darbera L, Chenoune M, Lidouren F, Kohlhauer M, Adam C, Bruneval P, Ghaleh B, 271 Dubois-Rande JL, Carli P, Vivien B, Ricard JD, Berdeaux A, Tissier R: Hypothermic liquid 272 ventilation prevents early hemodynamic dysfunction and cardiovascular mortality after 273 coronary artery occlusion complicated by cardiac arrest in rabbits. Crit Care Med In 274 press, 2013.

275 11. Boddicker KA, Zhang Y, Zimmerman MB, Davies LR, Kerber RE: Hypothermia 276 improves defibrillation success and resuscitation outcomes from ventricular fibrillation. 277 Circulation $111(24): 3195-3201,2005$.

278 12. Freese J, NYC Project Hypothermia Working Group: Abstract 2: Intra-arrest 279 Induction of Therapeutic Hypothermia via Large-Volume Ice-Cold Saline Infusion 280 Improves Immediate Outcomes for Out-of-Hospital Cardiac Arrest Circulation 124 A2, 2812011.

282 13. Garrett JS, Studnek JR, Blackwell T, Vandeventer S, Pearson DA, Heffner AC, Reades 283 R: The association between intra-arrest therapeutic hypothermia and return of 284 spontaneous circulation among individuals experiencing out of hospital cardiac arrest. 285 Resuscitation 82 (1):21-25, 2011.

286 14. Polderman KH: Mechanisms of action, physiological effects, and complications of 287 hypothermia. Crit Care Med 37 (Suppl) S186-S202, 2009. 
15. Riter HG, Brooks LA, Pretorius AM, Ackermann LW, Kerber RE: Intra-arrest hypothermia: both cold liquid ventilation with perfluorocarbons and cold intravenous saline rapidly achieve hypothermia, but only cold liquid ventilation improves resumption of spontaneous circulation. Resuscitation 80 (5):561-566, 2009.

16. Mustafa S, Thulesius 0: Cooling-induced carotid artery dilatation: an experimental study in isolated vessels. Stroke 33 256-260, 2002.

17. Schmoker JD, Terrien Iii C, McPartland KJ, Boyum J, Wellman GC, Trombley L, Kinne J: Cerebrovascular response to continuous cold perfusion and hypothermic circulatory arrest. The Journal of Thoracic and Cardiovascular Surgery 137 (2):459-464, 2009.

18. Dabire H, Barthelemy I, Blanchard-Gutton N, Sambin L, Sampedrano CC, Gouni V, Unterfinger Y, Aguilar P, Thibaud JL, Ghaleh B, Bize A, Pouchelon JL, Blot S, Berdeaux A, Hittinger L, Chetboul V, Su JB: Vascular endothelial dysfunction in Duchenne muscular dystrophy is restored by bradykinin through upregulation of eNOS and nNOS. Basic Res Cardiol 107 (1):240, 2012.

19. Scolletta S, Taccone FS, Nordberg P, Donadello K, Vincent JL, Castren M: Intra-arrest hypothermia during cardiac arrest: a systematic review. Crit Care 16 (2):R41, 2012.

20. Staffey KS, Dendi R, Brooks LA, Pretorius AM, Ackermann LW, Zamba KD, Dickson E, Kerber RE: Liquid ventilation with perfluorocarbons facilitates resumption of spontaneous circulation in a swine cardiac arrest model. Resuscitation 78 (1):77-84, 2008.

21. Cho JH, Ristagno G, Li Y, Sun S, Weil MH, Tang W: Early selective trans-nasal cooling during CPR improves success of resuscitation in a porcine model of prolonged pulseless electrical activity cardiac arrest. Resuscitation 82 (8):1071-1075, 2011. 
311 22. Wang H, Barbut D, Tsai MS, Sun S, Weil MH, Tang W: Intra-arrest selective brain

312 cooling improves success of resuscitation in a porcine model of prolonged cardiac arrest.

313 Resuscitation 81 (5):617-621, 2010.

314 23. Derwall M, Westerkamp M, Lower C, Deike-Glindemann J, Schnorrenberger NK,

315 Coburn M, Nolte KW, Gaisa N, Weis J, Siepmann K, Hausler M, Rossaint R, Fries M:

316 Hydrogen sulfide does not increase resuscitability in a porcine model of prolonged 317 cardiac arrest. Shock 34 (2):190-195, 2010.

318 24. Ristagno G, Fumagalli F, Russo I, Tantillo S, Zani DD, Locatelli V, De Maglie M, Novelli 319 D, Staszewsky L, Vago T, Belloli A, Di Giancamillo M, Fries M, Masson S, Scanziani E, 320 Latini R: Post-Resuscitation Treatment With Argon Improves Early Neurological 321 Recovery in a Porcine Model of Cardiac Arrest. Shock 2013.

322 25. Omar YG, Massey M, Andersen LW, Giberson TA, Berg K, Cocchi MN, Shapiro NI, 323 Donnino MW: Sublingual microcirculation is impaired in post-cardiac arrest patients.

324 Resuscitation 2013.

325 26. Schortgen F, Clabault K, Katsahian S, Devaquet J, Mercat A, Deye N, Dellamonica J, 326 Bouadma L, Cook F, Beji O, Brun-Buisson C, Lemaire F, Brochard L: Fever control using 327 external cooling in septic shock: a randomized controlled trial. Am J Respir Crit Care Med 328185 (10):1088-1095, 2012. 


\begin{tabular}{|c|c|c|c|c|c|c|c|c|}
\hline & \multicolumn{4}{|c|}{ Baseline } & \multicolumn{4}{|c|}{$\begin{array}{l}\text { Cardiopulmonary resuscitation } \\
\text { ( } t=3 \mathrm{~min})\end{array}$} \\
\hline & Control & $\begin{array}{l}\text { Saline } \\
4^{\circ} \mathrm{C} \\
\end{array}$ & $\begin{array}{l}\text { Saline } \\
38^{\circ} \mathrm{C}\end{array}$ & Adrenaline & Control & $\begin{array}{l}\text { Saline } \\
4^{\circ} \mathrm{C} \\
\end{array}$ & $\begin{array}{l}\text { Saline } \\
38^{\circ} \mathrm{C}\end{array}$ & Adrenaline \\
\hline \multicolumn{9}{|c|}{ Heart rate (beats/min) } \\
\hline & $256 \pm 7$ & $260 \pm 9$ & $254 \pm 8$ & $260 \pm 8$ & $244 \pm 7$ & $242 \pm 8$ & $245 \pm 11$ & $251 \pm 7$ \\
\hline \multicolumn{9}{|c|}{ Arterial pressure $(\mathrm{mmHg})$} \\
\hline Max & $103 \pm 7$ & $104 \pm 4$ & $102 \pm 3$ & $107 \pm 4$ & $62 \pm 2$ & $57 \pm 4$ & $51 \pm 3$ & $92 \pm 11 *$ \\
\hline Mean & $83 \pm 10$ & $84 \pm 7$ & $89 \pm 4$ & $90 \pm 5$ & $26 \pm 2$ & $30 \pm 7$ & $25 \pm 1$ & $51 \pm 6^{*}$ \\
\hline Min & $72 \pm 10$ & $70 \pm 4$ & $78 \pm 4$ & $79 \pm 5$ & $2 \pm 2$ & $6 \pm 2$ & $6 \pm 1$ & $19 \pm 9 *$ \\
\hline \multicolumn{9}{|c|}{ Venous pressure $(\mathrm{mmHg})$} \\
\hline Max & $6 \pm 1$ & $6 \pm 1$ & $4 \pm 1$ & $5 \pm 1$ & $57 \pm 10$ & $38 \pm 9$ & $54 \pm 13$ & $60 \pm 11$ \\
\hline Mean & $4 \pm 1$ & $5 \pm 1$ & $3 \pm 1$ & $3 \pm 1$ & $22 \pm 3$ & $18 \pm 4$ & $17 \pm 4$ & $16 \pm 4$ \\
\hline Min & $2 \pm 1$ & $3 \pm 1$ & $1 \pm 1$ & $1 \pm 1$ & $-1 \pm 1$ & $2 \pm 2$ & $-4 \pm 3$ & $-3 \pm 2$ \\
\hline \multicolumn{9}{|c|}{ Maximal difference between arterial and venous pressure ( $\mathrm{mmHg})$} \\
\hline & $101 \pm 6$ & $98 \pm 4$ & $99 \pm 3$ & $106 \pm 4$ & $36 \pm 4$ & $28 \pm 8$ & $33 \pm 5$ & $69 \pm 11 *$ \\
\hline \multicolumn{9}{|c|}{ End-tidal $\mathrm{CO}_{2}$ concentration in the expired air $(\mathrm{mmHg})$} \\
\hline & $43 \pm 7$ & $38 \pm 2$ & $40 \pm 2$ & $35 \pm 5$ & $21 \pm 7$ & $19 \pm 3$ & $18 \pm 2$ & $19 \pm 2$ \\
\hline \multicolumn{9}{|c|}{ Blood oxygen saturation (\%) } \\
\hline & 100 & $99 \pm 1$ & 100 & $99 \pm 1$ & $76 \pm 9$ & $71 \pm 5$ & $79 \pm 4$ & $78 \pm 6$ \\
\hline
\end{tabular}

333

$334 *, \mathrm{p}<0.05$ vs all other groups 


\section{LEGEND OF FIGURES}

338 Figure 1: Experimental protocol and body temperatures.

339 Panel A: Schematic representation of the experimental protocol. Animals were randomly 340 assigned to the following groups: "Control”, "Saline $4{ }^{\circ} \mathrm{C}$ ” (20 ml $/ \mathrm{kg}$ of cold $\mathrm{NaCl} 0.9 \%$ i.v.),

341 "Saline $38^{\circ} \mathrm{C}^{\prime}$ (20 ml/kg of warm NaCl 0.9\% i.v.), or "Adrenaline" (boluses of $15 \mathrm{\mu g} / \mathrm{kg}$ i.v.).

342 Panel B: Body temperatures throughout protocol in the different groups.

$343 C P R$, cardiopulmonary resuscitation; Temp., temperature; VF, ventricular fibrillation; *,

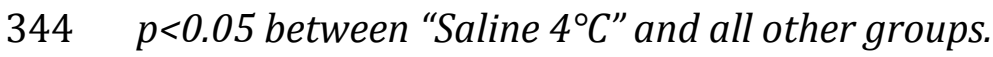

346 Figure 2: Rate and frequency of successful defibrillation and resumption of spontaneous 347 circulation (ROSC).

348 Panel A: Overall frequency of successful defibrillation, ROSC and haemoptysis appearance 349 during cardiopulmonary resuscitation efforts.

350 Panel B: Rate and frequency of successful defibrillation during cardiopulmonary 351 resuscitation efforts.

352 Panel C: Rate and frequency of ROSC during cardiopulmonary resuscitation efforts.

$353 \quad *, p<0.05$ vs all other groups.

355 Figure 3: In vitro investigations at two different temperatures (32 vs $38^{\circ} \mathrm{C}$ ) of the 356 vascular function of aorta rings sampled from healthy rabbits (Sham groups) or after 357 cardiac arrest

358 Panel A: Contraction of the aorta rings in response to increasing concentrations of noradrenaline (tension expressed in g). 
360 Panel B: Vasodilating response to acetylcholine and sodium nitroprusside (expressed 361 in \% of the maximal contraction induced by noradrenaline).

$362 *, p<0.05$ vs Sham at the same temperature.

363 


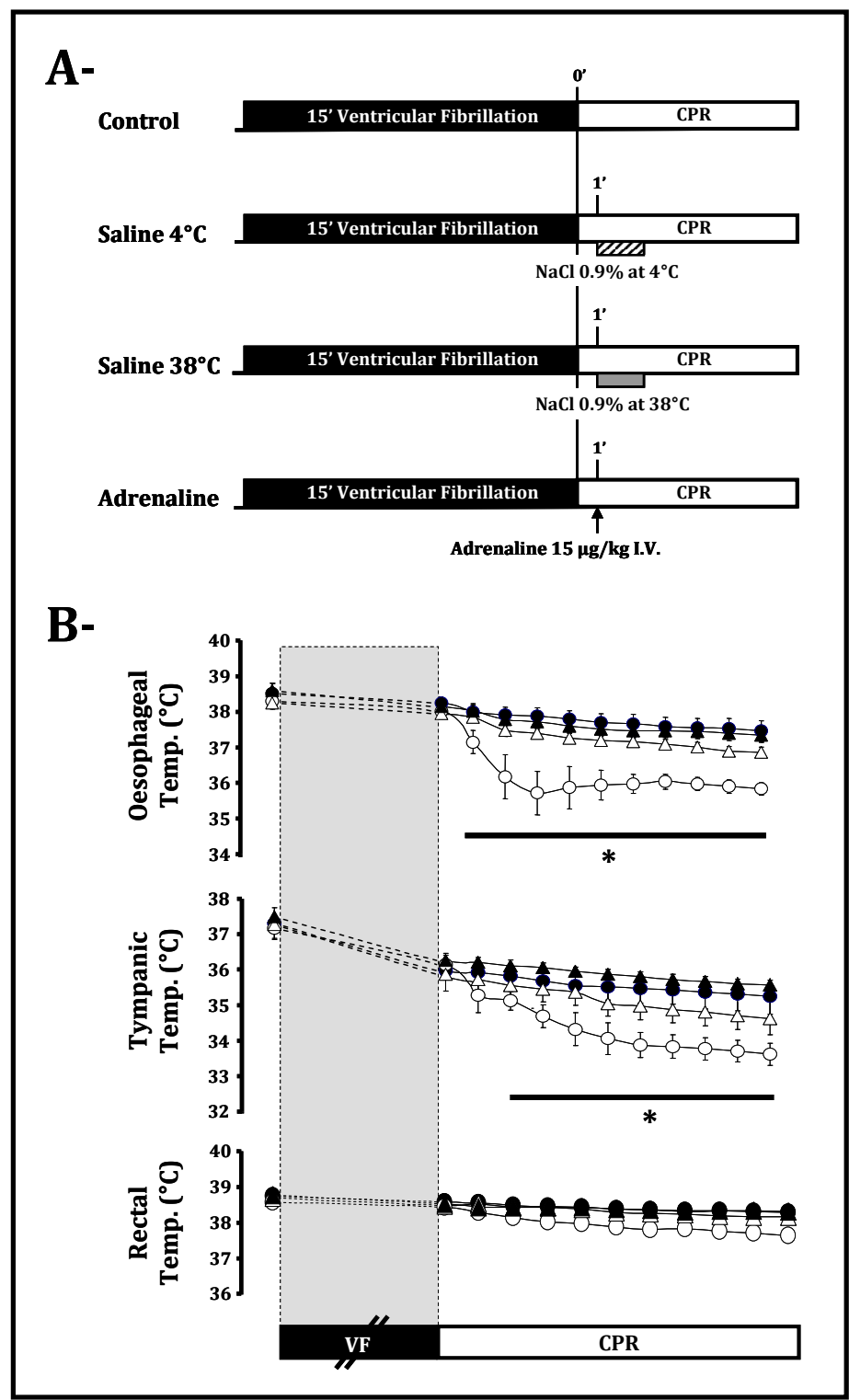




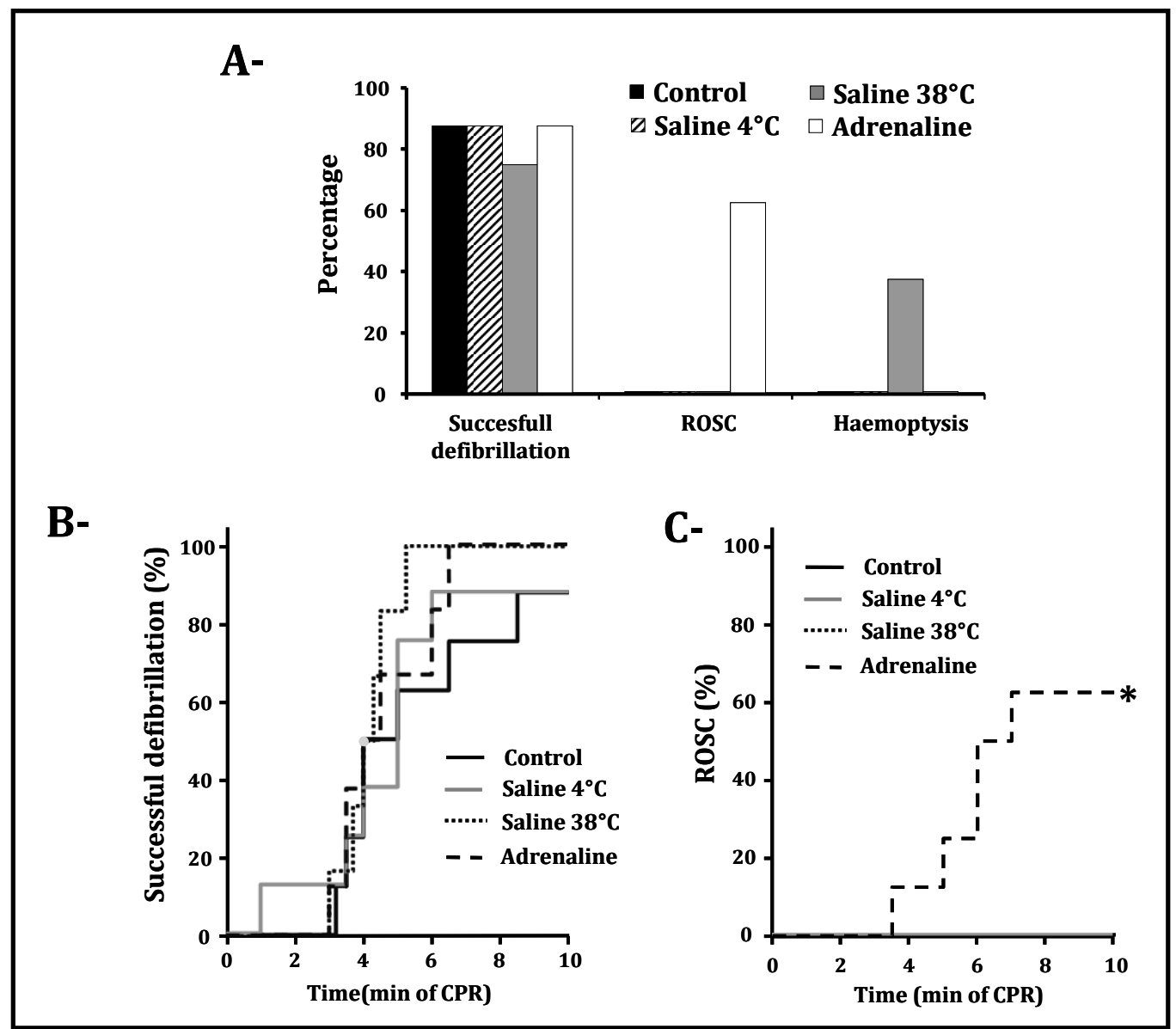




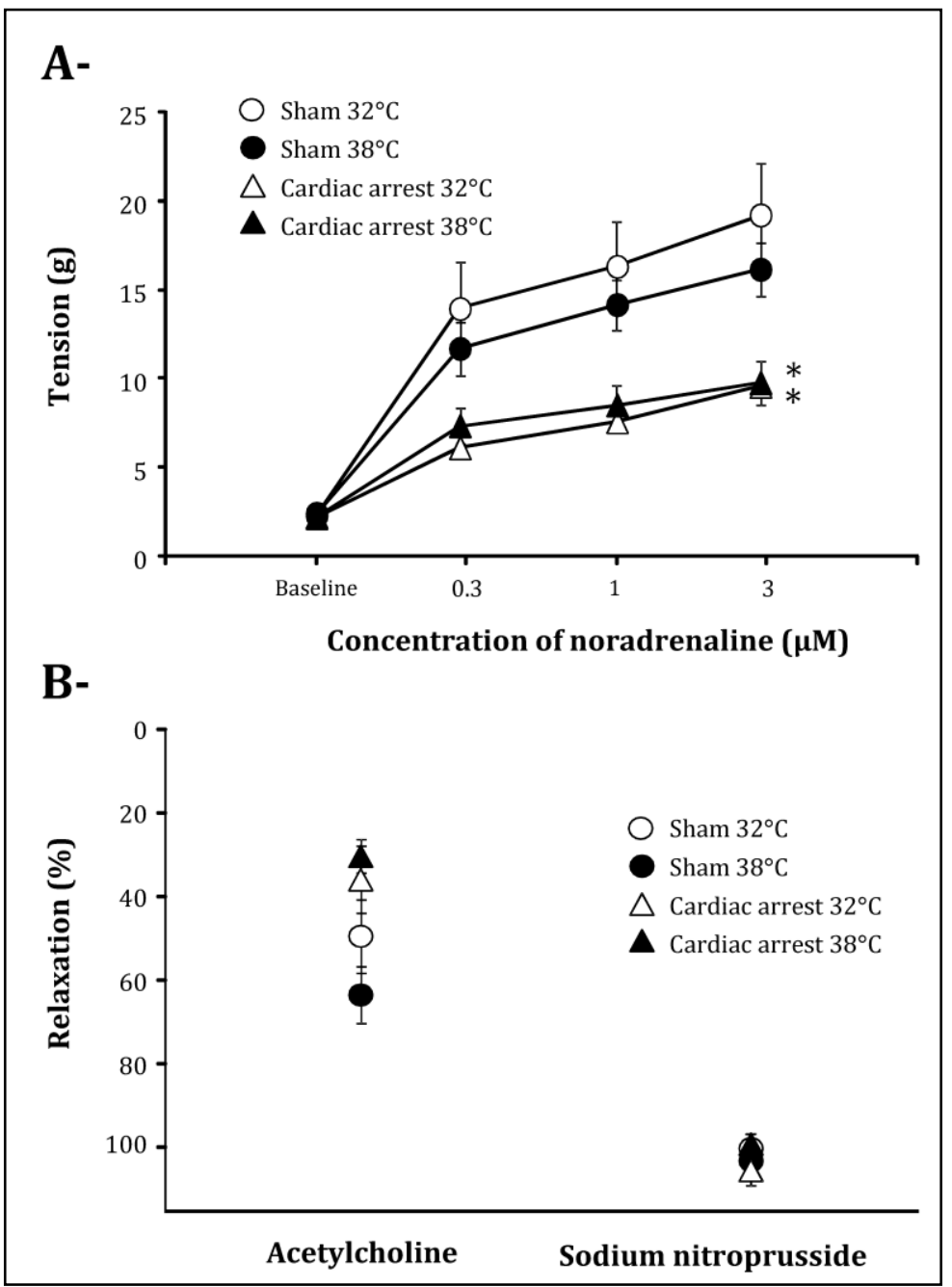

